\title{
Non-invasive and husbandry treatment in a singular post-ovulatory eggs stasis on an Asian water monitor (Varanus salvator)
}

\author{
Puveanthan Nagappan Govendan ${ }^{1, *}$, Zefanya Christiani ${ }^{2}$, Michael Nadhor Nainggolan ${ }^{3}$ \\ Slamet Raharjo ${ }^{4}$ \\ ${ }^{1}$ Faculty of Veterinary Medicine, Gadjah Mada University, Yogyakarta, Indonesia \\ ${ }^{2}$ Faculty of Veterinary Medicine, Udayana University, Bali, Indonesia \\ ${ }^{3}$ Sunset Vet Bali, Bali, Indonesia \\ ${ }^{4}$ Department of Internal Medicine, Faculty of Veterinary Medicine, Gadjah Mada University, Yogyakarta, Indonesia
}

ABSTRACT: Asian water monitor (Varanus salvator) is among the largest species of monitor lizards kept in captivity due to the elegancy and character of the species. Captive breeding projects of monitor lizards are not common among reptile keepers. A two years old female $V$. salvator was presented with complains of anorexic and distended abdomen. No record of copulation or egg deposition was noticed from the particular specimen. Radiography confirmed a post-ovulatory egg-stasis (POES) occurring in the coelomic cavity. Fluid therapy and husbandry improvement was indicated as treatments. Oviposition of the POES was noticed 4 days after treatment. Young monitors could be prone to have less quantity of eggs but larger in size.

Keywords:

Varanus salvator, radiography, post-ovulatory egg stasis, oviposition

\section{- INTRODUCTION}

Asian water monitor ( $V$. salvator) is a saurian commonly kept in captivity in private or zoo collection in Indonesia. Being one of the biggest varanid, they have a tendency to be very calm in captive either if they are captive raised or kept as juveniles with lots of physical attention but at the same time they can be really aggressive while feeding. Varanus salvator is an ovipa-rous reptile which lays about 5-22 eggs (Shine et al. 1996) and 6-17 eggs (Kulabtong and Mahaprom 2015) in one clutch.

A 2 year old $V$. salvator with complains of anorexic for about 4 days and distended abdomen. No records of courtship or mating happened. Particular lizard was placed with other sub-adult female $V$. salvator. Radiography imaging confirmed presence of a single egg in the coelomic cavity. Non-invasive treatment method of treating was approached in this case. Post-ovulatory egg stasis happens with the inability of the body to do oviposition in captivity due to husbandry and pathologic related problems (Bellese 2017). Stahl (2006) mentioned that dystocia in lizards are more commonly in oviparous lizards compared to ovoviviparous lizards.

\section{- CASE}

Signalmen: A $1.8 \mathrm{~kg}$ albino female $V$. salvator (Fig. 1A). Anamneses: The owner got the $V$. salvator when it was still a juvenile. The monitor was kept for around one year plus in a semi indoor enclosure together with 2 other females and never been placed with any adult male. The lizard was fed with fresh prawns, chicken necks and rats. The lizard was not consuming food like before and hind leg weakness was noticed. Physical Examination: The monitor lizard was active and bright. Mucous membrane was slightly pale. Abdomen was inspected and coelomic cavity palpated to be distended. Hind legs were manually fixated and were normal but paresis was noticed sometimes while moving.

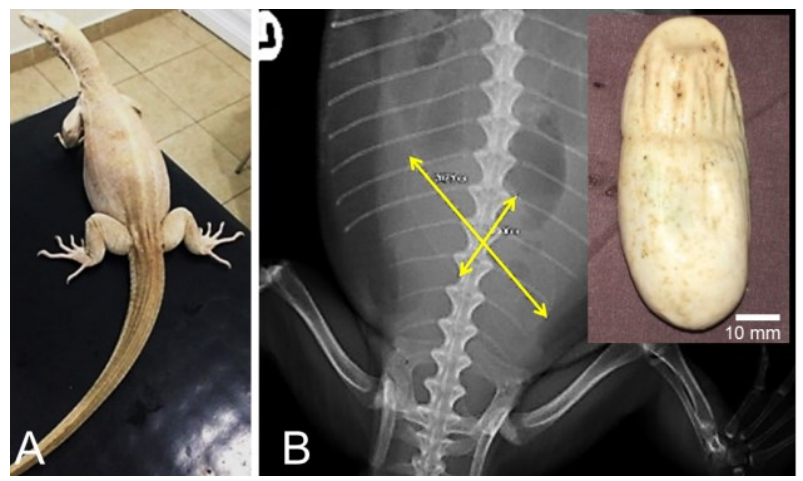

Figure 1 The female water monitor ( $V$. salvator $)(\mathrm{A})$ and ventral recumbence radiography image with post-ovulatory egg-stasis (B) that the infertile egg delivered on day 4 (inset).

Received: 10-02-2020 | Revised: 15-03-2020 | Accepted: 20-03-2020

(C) 2020 CC-BY-SA. This is an Open Access article that is distributed under the terms of Creative Commons Attribution ShareAlike 4.0 International License (https://creativecommons.org/licenses/by-sa/4.0/). 
Radiography: Radiography was performed with the $V$. salvator on the dorsoventral (DV) (Figure 1B) and lateral view without anesthesia. Radiography showed one shelled egg being more radiopaque and with a length of $7 \mathrm{~cm} \times 3$ $\mathrm{cm}$ in the caudal part of the coelomic cavity. Diagnosis: Based on the clinical symptoms and radiology, it was diagnosed with post-ovulatory egg stasis (POES). Prognosis: The prognosis in this case was guarded (fausta-dubius). Treatment: Husbandry improvement of nesting box filled with sand placed in the enclosure. The monitor was given only supportive fluids of $\mathrm{NaCl} 0.9 \%$ with a dose of 20 $\mathrm{mL} / \mathrm{kg}$ BW refer to Knotek et al. (2017) subcutaneously on both the hind legs. Owner was advised to do close observation back at home with placing a nest box into the monitor's enclosure. If no signs of egg laying or straining was noticed within 3-5 days, owner was advised to bring back for oxytocin and calcium gluconate treatment or surgical removal. The monitor eventually oviposition the single infertile egg (Figure 1B inset) after husbandry improvement on day 4.

\section{DISCUSSION}

The $V$. salvator was placed together with females and this could have induced the ovarian follicles to develop and become infertile eggs, where the size of the egg may reach a large ovulatory egg size. The reason for this is still unclear but might be related to environmental condition. Reptiles in general will go anorexic in gravid condition and a few days before oviposition (Stahl 2006). Bilateral hind legs paresis and abdominal distention is a sign of egg binding in lizards (Love et al. 1996). Palpation of the ova against the body wall was not possible.

An radiography revealed a post-ovulatory egg stasis occurred at the caudal part of the coelomic cavity. This could be the reason for the bilateral hind leg paresis due to pain caused by the singular POES. Radiographic imaging is useful for egg retention diagnosis (Love et al. 1996; Divers 2006; Stahl 2006; Knotek 2015; Giuseppe et al. 2017).

Fluid therapy was given subcutaneously divided on both hind legs with a dose of $20 \mathrm{~mL} / \mathrm{kg}$ for maintaining the body fluids (Knotek et al. 2017). Clinically the $V$. salvator was still active and tongue was forking out normally. Noninvasive treatment and husbandry improvement was indicated in this case. Sexually maturity in captive animals could occur at early age due to the care and diet compared to age maturity for reproducing (Knotek et al. 2017). Young varanid which achieve earlier sexual maturity usually produce bigger egg but in lesser quantity (Thompson \& Pianka 2001).

\section{- CONCLUSION}

Egg stasis in $V$. salvator is possible due to many reasons. Radiography is an important diagnostic method for postovulatory egg stasis in lizards. Husbandry improvement should always be a treatment plan in reptile with dystocia. Non-invasive treatment could give satisfying results on a clinically healthy lizard with close observation of condition and supportive treatment if started early. Oviposition happened after non-invasive treatment and environment improvement.

\section{- AUTHOR INFORMATION}

Corresponding Author

*PNG: puvean89@gmail.com

Faculty of Veterinary Medicine, Gadjah Mada University, Yogyakarta, Indonesia

\section{- REFERENCES}

Bellese A. 2017. Follicular stasis and dystocia in reptiles. AVIPA Journal 2/2017:8-20.

Divers SJH. 2006. Reptile radiology: Techniques, tips and pathology. The North American Veterinary Conference 20:1626-1630.

Giuseppe MD, Silvestre AM, Luparello M, Faraci L. 2017. Postovulatory dystocia in two small lizards: Leopard gecko (Eublepharis macularis) and crested gecko (Correlophus ciliatus). Russian Journal of Herpetology 24(2):128-132.

Knotek Z. 2015. Reproduction surgery in female Asian pythons. In 40th World Small Animal Veterinary Association Congress, Bangkok, Thailand, 15-18 May, 2015. Proceedings book 2015 (pp. 259260). WSAVA 2015 Congress - VIN.

Knotek Z, Cermakova E, Oliveri M. 2017. Reproductive medicine in lizards. Veterinary Clinics: Exotic Animal Practice 20(2):411-438.

Kulabtong S, Mahaprom R. 2015. Observation on Food Items of Asian Water Monitor, Varanus salvator (Laurenti, 1768) (Squamata Varanidae), in urban eco-system, Central Thailand. Biodiversity Journal 6(3):695-698.

Love NE, Douglass JP, Lewbart G, Stoskopf M. 1996. Radiographic and ultrasonographic evaluation of egg retention and peritonitis in two green iguanas (Iguana iguana). Veterinary Radiology \& Ultrasound 37(1):68-73.

Shine R, Harlow PS, Keogh JS, Boeadi. 1996. Commercial harvesting of giant lizards: The biology of water monitors Varanus salvator in southern Sumatra. Biological Conservation 77(2-3):125-134.

Stahl SJ. 2006. Reptile Obstetrics. The North American Veteri-nary Conference 20:1680-1683.

Thompson GG, Pianka ER. 2001. Allometry of clutch and neonate sizes in Monitor Lizards (Varanidae: Varanus). Copeia 2001(2):443458 . 
